\title{
STUDY ON THE PROPERTIES OF POLYURETHANE-CEMENT COMPOSITE (PUC)
}

\author{
Kexin Zhang ${ }^{1,2}$, Dachao $L i^{2}$, Tianyu Qi ${ }^{2}$, Yanfeng $L i^{2}$ and Xingwei Xue ${ }^{2}$
}

\author{
1. MOE Key Lab of Disaster Forecast and Control in Engineering, Jinan \\ University, No.601 Huangpu Dadao West, Guangzhou, Guangdong Province, \\ China;jt_zkx@sjzu.edu.cn \\ 2. School of Traffic Engineering, Shenyang Jianzhu University, No.25 Hunnan \\ Zhong Road, Shengyang, Liaoning Province, China
}

\begin{abstract}
In order to study the properties of polyurethane cement composite (PUC) material, this paper has carried out the tests of compressive resistance, flexural resistance, axial tension, bonding and acid and alkali corrosion resistance of the material. The average compressive strength of the material is $59.3 \mathrm{MPa}$, the average flexural strength is $41.5 \mathrm{MPa}$, and the average axial tensile strength is 31.0 $\mathrm{MPa}$. The bonding strength between the material and concrete in axial tension is $3.56 \mathrm{MPa}$, and that between the material and concrete in bending is 3.16 MPa. The failure interface of the two bond tests is not on the bond surface, indicating that the polyurethane cement composite (PUC) material has good bonding property. The chemical corrosion resistance test of polyurethane cement material showed no visible change on the surface of the material, indicating good chemical corrosion resistance.
\end{abstract}

\section{KEYWORDS}

Polyurethane cement, Mechanical property, Acid and alkali resistance, Adhesive property

\section{INTRODUCTION}

Bridge is an important part of highway transportation and plays an important role in highway transportation. With the continuous development of social economy and increasingly busy transportation, bridge as the throat of highway traffic plays an irreplaceable role [1-3]. With the development of social economy, the transportation industry is unprecedentedly prosperous. As the carrier of transportation, the vehicle has undergone great changes compared to the past, with the increase of vehicle load and flow being the most obvious. Due to the rapid increase of vehicle load, coupled with the influence of acid rain, air and temperature and other natural conditions, the bridge structure has produced a series of diseases such as stress crack, concrete deterioration, steel corrosion and so on [4-6]. These man-made and natural factors affect the bridge to varying degrees, mainly reflected in the safety, applicability and durability of the structure, and finally reduce the bearing capacity of the bridge, endangering the long-term operation of the bridge [7-11].

Bridge superstructure reinforcement methods include section enlargement method, bonding high-strength composite fiber material, bonding steel plate method, reinforcement method of external unbonded prestressed steel strand [12-15]. The section enlargement method is a traditional reinforcement method, which has the advantages of simple construction and strong adaptability, but the wet work workload is large, the construction maintenance period is long, the dead weight increases greatly, and the traffic is greatly affected. The reinforcement method of sticking steel plate can give full play to the tensile performance of steel and the compressive performance of masonry materials. The construction is simple, the construction period is short, and the influence on traffic is 


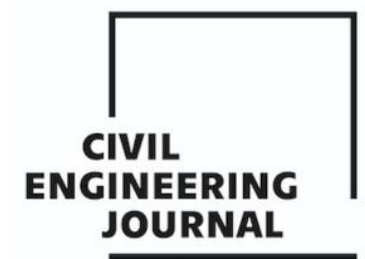

Article no. 42

THE CIVIL ENGINEERING JOURNAL 2-2021

small. However, the steel plate is difficult to adapt to the uneven concrete surface, and it is easy to rust in the natural environment. The bonded fiber material method is simple in construction and has little influence on the original structure as a whole. In the microscopic aspect, the physical and chemical properties of the carbon fiber composite are stable and can resist the harsh environment. However, the carbon fiber cloth/board is relatively thin, which does not significantly improve the structural stiffness and the material cost is high. Prestressed steel strand reinforcement method can make the bearing capacity and stiffness increase more obviously, but it has the disadvantage of being greatly affected by the site and component conditions, and the construction is very troublesome.

Polyurethane cement composite (PUC) material has the characteristics of early strength and convenient construction, which is used for structural reinforcement by scholars. Yang Yongqing [16] studied the bridge performance after the reinforcement of pouring polyurethane concrete, and the results showed that the transverse load distribution influence line of the reinforced hollow slab bridge was gentler than that before the reinforcement, and the overall transverse mechanical performance of the bridge was significantly improved. Guiwei et al. [17] obtained polyurethane concrete composite material through material preparation, and reinforced Zhejiang Baixi Bridge with PUC material. The results show that polyurethane concrete material can better improve the bearing capacity of the structure and can carry out construction operations without the traffic being stopped. Zhang Hongxiang et al. [18] took Zhongxing Bridge as an example to carry out an experimental study on the bearing capacity of bridges reinforced with polyurethane concrete, showing that the bearing capacity and stiffness of bridges reinforced with polyurethane concrete have been greatly improved. Gao Feng [19] carried out bending reinforcement test of PUC material for 13 m hollow slab beams, and no slip between PUC material and concrete section appeared in the whole test process. Formulas for calculating the strain and flexural capacity of hollow slab beams reinforced by PUC are established. Gu Dandan et al. [20, 21] carried out load tests on the reinforced hollow slab girder bridge, and the test results showed that the strength and stiffness of the reinforced structure were significantly improved. Haleem K et al. [22-24] used polyurethane cement (PUC) composites to carry out flexural reinforcement tests on $7 \mathrm{~T}$-section beams with different damage degrees, and the results showed that the ultimate bearing capacity of the beams strengthened with PUC could be significantly improved and the cracks of the beams could be significantly reduced.

At present, the research on PUC mainly focuses on the reinforcement of bridge structures, the study of polyurethane cement composite is not comprehensive enough. In order to make PUC get better application, the mechanical properties and acid and alkali corrosion resistance of polyurethane cement material were systematically studied in this paper.

\section{METHODS PUC RAW MATERIALS AND RATIO}

\section{Polyurethane (PU)}

Polyurethane cement is a kind of polymer concrete material, its main component is polyurethane. Polyurethane is a polymer with excellent performance, mainly from the polymerization of isocyanates and polyols, the main raw material components are shown in Table 1.

The hardness range of polyurethane materials is 10-100 (IRHD), where 0 (IRHD) represents a modulus of elasticity of 0 , and 100 (IRHD) represents an infinite modulus of elasticity. Polyurethane material has good wear resistance, chemical corrosion resistance, fluidity, bonding and molding properties. A series of polyurethane cement materials were developed by measuring the density of the new material. 


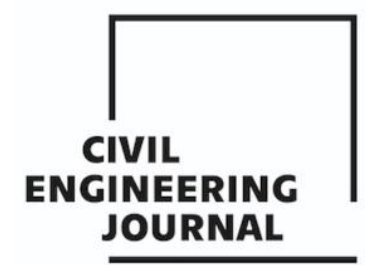

Article no. 42

THE CIVIL ENGINEERING JOURNAL 2-2021

Tab. 1 - Main chemical composition of polyurethane

\begin{tabular}{|c|c|c|}
\hline \multirow{2}{*}{ Chemical Constitution } & Percentage (\%) \\
\cline { 2 - 3 } polyhydric alcohols & Polyether & 49 \\
\cline { 2 - 3 } & Silicone oil & 1 \\
\cline { 2 - 3 } & water & $0-1$ \\
\hline isocyanate & & $50-51$ \\
\hline
\end{tabular}

\section{Polyurethane cement composite (PUC)}

Polyurethane cement composite (PUC) raw materials in accordance with the quality ratio of mixing and polymerization reaction, polyol: isocyanate: cement $=1: 1: 2$ (mass ratio). High density polyurethane cement material was prepared, as shown in Table 2. Polyol, isocyanate and cement were the main raw materials in the mixture ratio. The polyurethane cement material was cured in dry environment for $7 \mathrm{~d}$. The production process of PUC is shown in Figure 1 and Figure 2.

Tab. 2 - Composition of PUC

\begin{tabular}{|c|c|}
\hline PUC & Percentage (\%) \\
\hline Polyether polyol & 25 \\
\hline Isocyanate & 25 \\
\hline Cement & 50 \\
\hline
\end{tabular}

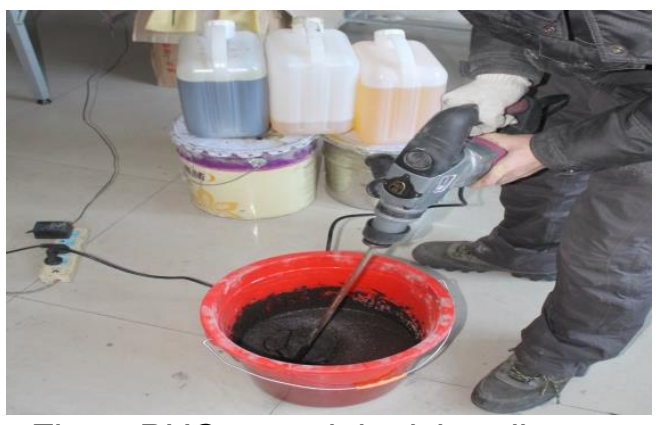

Fig. 1- PUC material mixing diagram

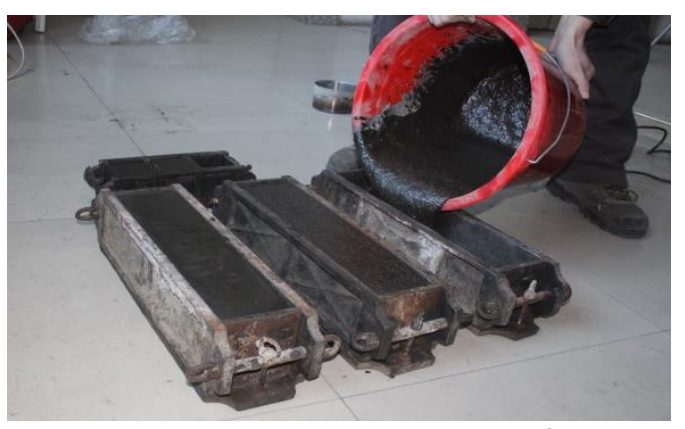

Fig. 2- Pouring drawing of PUC

\section{MATERIAL CHARACTERISTIC TEST}

\section{Test content}

In this paper, starting from the properties of PUC material, the corresponding stress-strain curve is obtained through compressive test, flexural test and axial tensile test. The bonding strength and failure mode under different stress forms are obtained through axial tensile bonding test and bending bonding test. Finally, the PUC material was placed in different concentrations of acid and alkali solutions, and the acid and alkali corrosion resistance of the material was analyzed by testing the mass loss and apparent appearance of the specimen

\section{Compression and bending test}

\section{Compression and flexural strength}

In order to study the mechanical properties of PUC, $1550 \mathrm{~kg} / \mathrm{m}^{3}$ PUC material with high compressive strength and flexural strength was selected as the research object in this paper. The polyurethane cement material with a density of $1550 \mathrm{~kg} / \mathrm{m}^{3}$ is expressed as PUC-1550, with the matching as shown in Table 3 . The compressive strength test adopts the cube test with the size of $70 \mathrm{~mm} \times 70 \mathrm{~mm} \times 70 \mathrm{~mm}$, and the bending strength adopts the rectangular test with the size of $450 \mathrm{~mm} \times 100 \mathrm{~mm} \times 100 \mathrm{~mm}$. Resistance strain gauges are pasted on the surface of the cube block along the horizontal and vertical sides respectively to measure the horizontal and vertical strain changes of the cube block in the process of compression. In the middle position of the cuboid, 


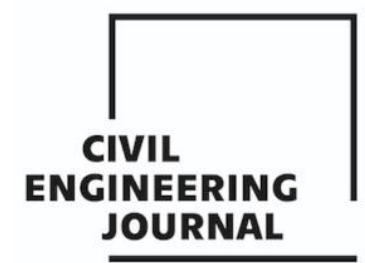

Article no. 42

THE CIVIL ENGINEERING JOURNAL 2-2021

resistance strain gauges are arranged on the top surface, the bottom surface and the middle position respectively along the horizontal direction to test the strain changes at the top edge and bottom edge of the specimen during the bending resistance process.

Firstly, the polyurethane raw material and cement are poured into the container according to the mass proportion, and the material is mixed evenly with an electric stirring rod for $3 \mathrm{~min}$. Then the material is poured into the steel test mold and cured for $7 \mathrm{~d}$ under dry conditions. Compressive strength and flexural strength tests of PUC were carried out according to specification JTG E302005. Figure 3 and Figure 4 are the test drawings of the compressive strength and flexural strength of cubes. The resistance strain gauge is attached to the surface of the cube block and the prism block to measure the strain value during the loading process. The compressive strength and flexural strength tests of PUC-1550 material are shown below.

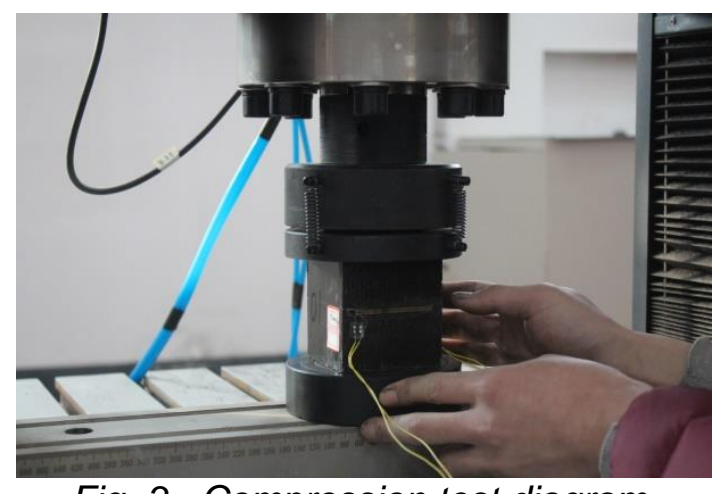

Fig. 3 - Compression test diagram

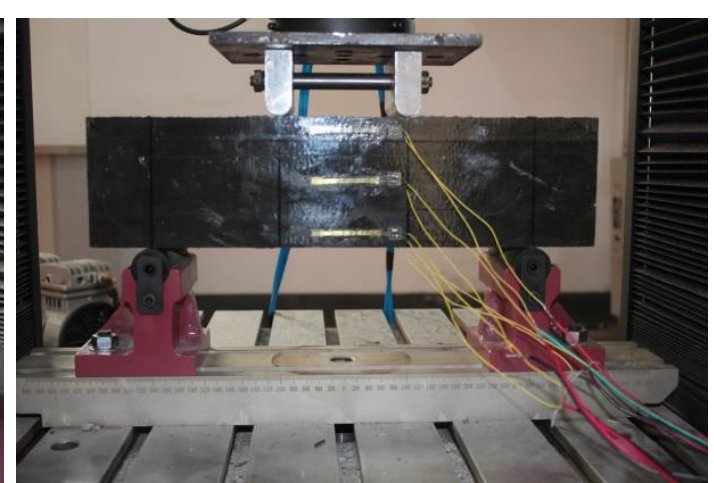

Fig. 4 - Flexural test diagram

The compressive strength and flexural strength of PUC-1550 are shown in Table 4 and Table 5. As can be seen from Table 3, the compressive strength of PUC with a density of $1507 \mathrm{~kg} / \mathrm{m}^{3} \sim 1588$ $\mathrm{kg} / \mathrm{m}^{3}$ is $57.8 \mathrm{MPa} \sim 60.6 \mathrm{MPa}$, with an average density of $1552 \mathrm{~kg} / \mathrm{m}^{3}$ and an average compressive strength of $59.3 \mathrm{MPa}$. According to Table 4, the flexural strength of PUC with a density of 1524 $\mathrm{kg} / \mathrm{m}^{3} \sim 1584 \mathrm{~kg} / \mathrm{m}^{3}$ is $39.6 \mathrm{MPa} \sim 43.3 \mathrm{MPa}$, with an average density of $1548 \mathrm{~kg} / \mathrm{m}^{3}$ and an average flexural strength of $41.5 \mathrm{MPa}$.

Tab. 3 - Compressive strength values of PUC-1550

\begin{tabular}{|c|c|c|c|c|c|c|c|}
\hline Number & F01 & F02 & F03 & F04 & F05 & F06 & $\begin{array}{c}\text { Average } \\
\text { Value }\end{array}$ \\
\hline Density $\left(\mathrm{kg} / \mathrm{m}^{3}\right)$ & 1507 & 1524 & 1544 & 1568 & 1579 & 1588 & 1552 \\
\hline Strength $(\mathrm{MPa})$ & 60.6 & 57.8 & 59.3 & 59.6 & 59.5 & 59.0 & 59.3 \\
\hline
\end{tabular}

Tab. 4 - Bending strength values of PUC-1550

\begin{tabular}{|c|c|c|c|c|c|c|c|}
\hline Number & $\mathrm{C} 01$ & $\mathrm{C} 02$ & $\mathrm{C} 03$ & $\mathrm{C} 04$ & $\mathrm{C} 05$ & $\mathrm{C} 06$ & $\begin{array}{c}\text { Average } \\
\text { Value }\end{array}$ \\
\hline Density $\left(\mathrm{kg} / \mathrm{m}^{3}\right)$ & 1524 & 1533 & 1546 & 1560 & 1577 & 1584 & 1548 \\
\hline Strength $(\mathrm{MPa})$ & 42.2 & 39.6 & 40.8 & 41.1 & 43.3 & 41.9 & 41.5 \\
\hline
\end{tabular}

\section{Compressive stress-strain curve}

The test was loaded by the universal testing machine, and the number of compressive specimens was six. The dynamic strain acquisition instrument was used for the collection. According to the measurement results of each test block, the compressive average stress-strain curve is obtained, as shown in Figure 6. At the initial loading stage, the stress-strain curve shows a linear relationship, the average compressive strength is $59.3 \mathrm{MPa}$, and the strain is $27956 \mu \varepsilon$. In the late loading stage, the stress-strain curve is nonlinear, and the strain at failure is $34612 \mu \varepsilon$. 

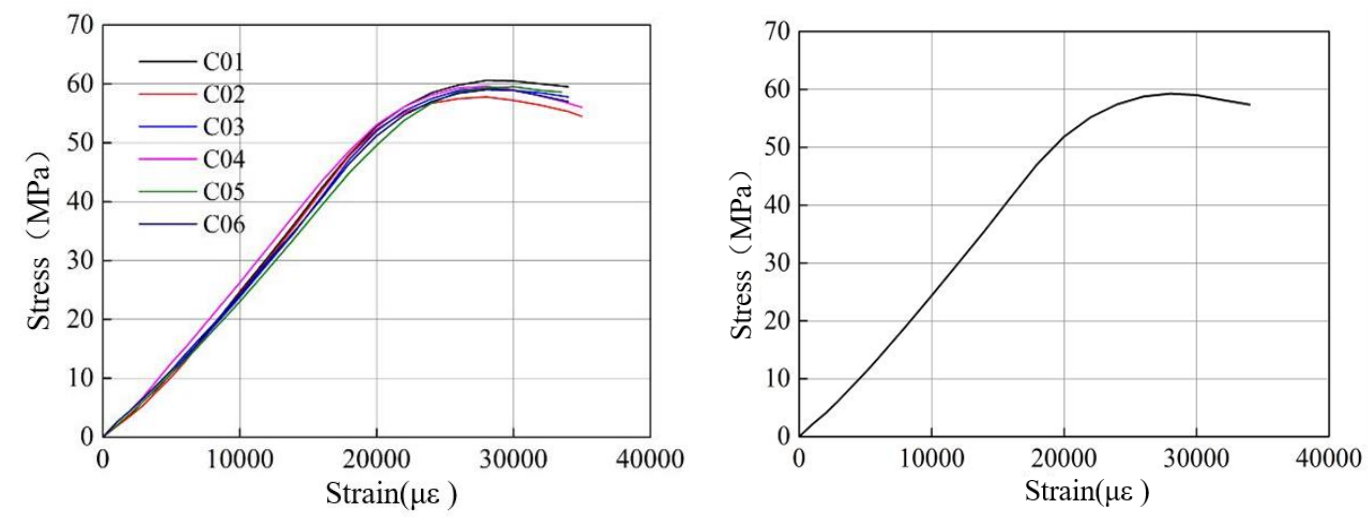

Fig. 5 - Compressive stress-strain curve

Fig. 6 - Compressive stress-strain curve (average)

\section{Blending stress-strain curve}

The flexural specimens were prismatic blocks, with a number of six, and were cured for $7 \mathrm{~d}$ under dry conditions. The dynamic strain acquisition instrument was used for data acquisition. The resistance strain gauges were pasted on the top surface, bottom surface and middle position of the test block, and the top surface was used to measure the compressive strain of the specimen in the bending process. The bottom surface measures the tensile strain of the specimen in the bending process, and the strain value is the average value of the measured values of the two resistance strain gauges in each test block. The bending stress-strain curve of each test block is shown in Figure 7. According to the tensile measurement results of each test block, the average stress-strain curve of tension is obtained, as shown in Figure 8. The average tensile strength is $41.5 \mathrm{MPa}$. According to the stress-strain curve, the elastic modulus of bending and tension was calculated to be $4300-5200 \mathrm{MPa}$.

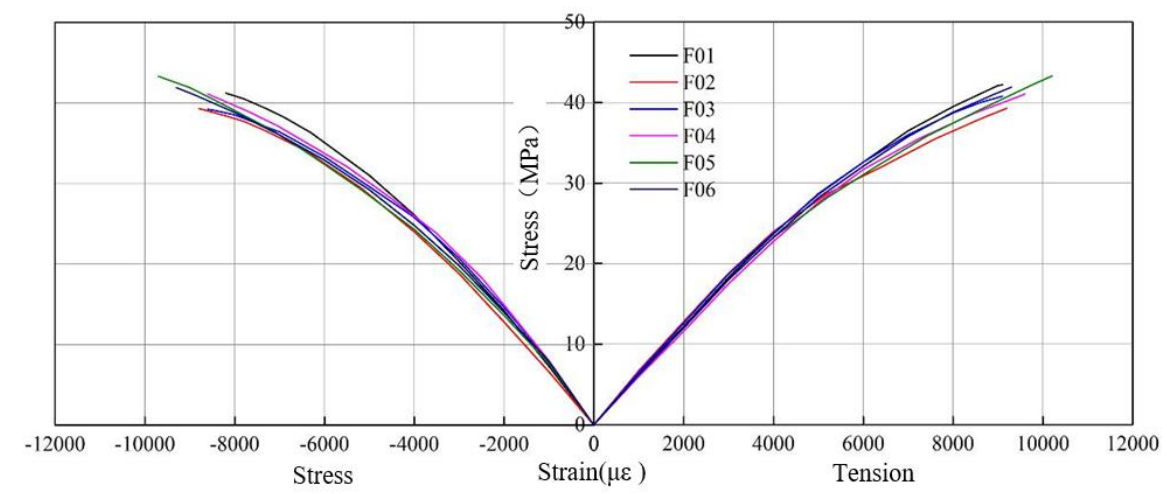

Fig. 7 - Flexural stress-strain curve

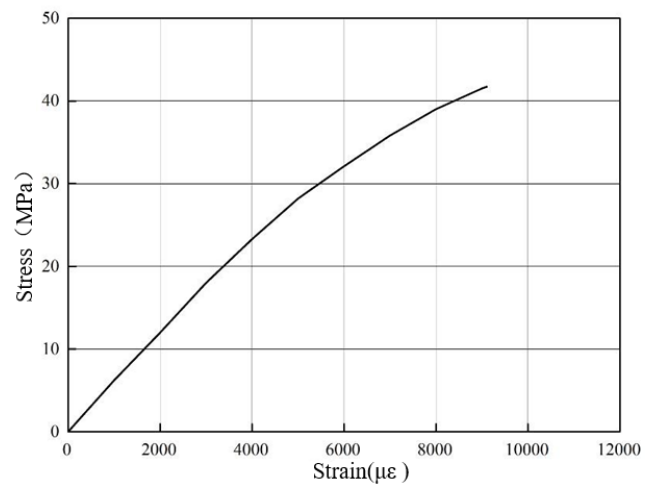

Fig. 8 - Tensile stress-strain curve (average) 
According to the stress and strain relationship points of the tensile side of the flexural specimen, the stress-strain relationship curve is fitted, as shown in Figure 9 . The fitting formula is as follows:

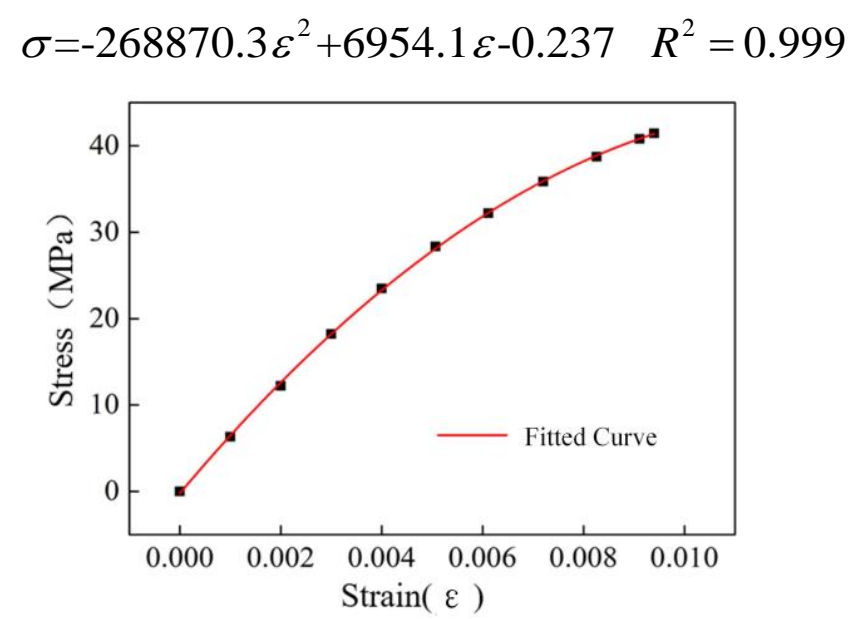

Fig. 9 - Stress-strain relationship fitting curve

Poisson of polyurethane cement material is shown in Figure 10, the average value of Poisson's ratio is a constant value $v=0.27$.

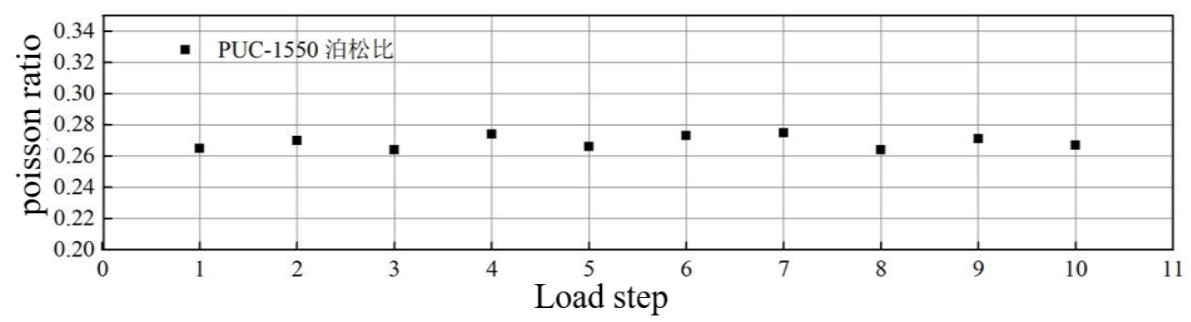

Fig. 10 - Poisson's ratio diagram of PUC

\section{Direct tensile test of material}

\section{Specimen making}

The specimen in this test is a dumbbell type sheet specimen with a thickness of $10 \mathrm{~mm}$, a middle width of $25 \mathrm{~mm}$ and a width of $40 \mathrm{~mm}$ on both sides, as shown in Figure 11 . The mold test in the pouring process is self-designed, as shown in Figure 12. The tensile test was carried out $7 \mathrm{~d}$ after the PUC material was cast. The tensile test was carried out on the small-range tester, and the loading speed was $50 \mathrm{~N} / \mathrm{s}$. The resistance strain gauge was pasted in the middle of the specimen and pasted symmetrically on both sides along the stretching direction to measure the strain change in the stretching process. The dynamic strain acquisition instrument was used for data acquisition.

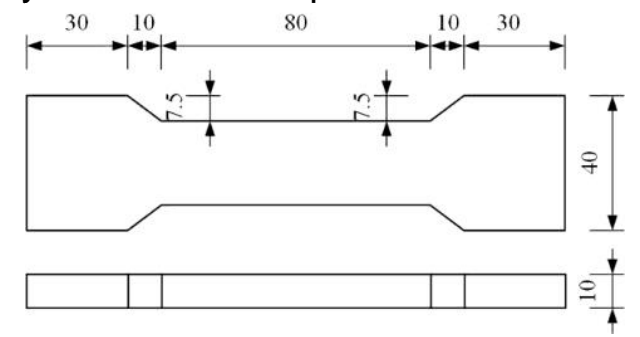

Fig. 11-Dimensions of PUC axial tensile specimen (unit: $\mathrm{mm}$ ) 


\section{Measurement results}

Tab. 5- PUC material axial tensile strength

\begin{tabular}{|c|c|c|c|c|c|c|c|}
\hline Number & ZL01 & ZL02 & ZL03 & ZL04 & ZL05 & ZL06 & $\begin{array}{c}\text { Average } \\
\text { Value }\end{array}$ \\
\hline $\begin{array}{c}\text { Strength (MPa } \\
\text { ( }\end{array}$ & 30.5 & 31.8 & 31 & 32.1 & 31.6 & 28.9 & 31.0 \\
\hline
\end{tabular}

According to the data in Table 5, the average axial tensile strength of polyurethane cement material is $31.0 \mathrm{MPa}$, and the straight-tension elastic modulus is calculated to be $4200-5700 \mathrm{MPa}$ according to the stress-strain curve.

According to the tensile force and the corresponding strain data collected during the test, the stress-strain relationship curves of the six specimens in straight tension were drawn, as shown in Figure 12. According to the straight-tension measurement results of the test block, the average stress-strain curve of axial tension is obtained, as shown in Figure 13.

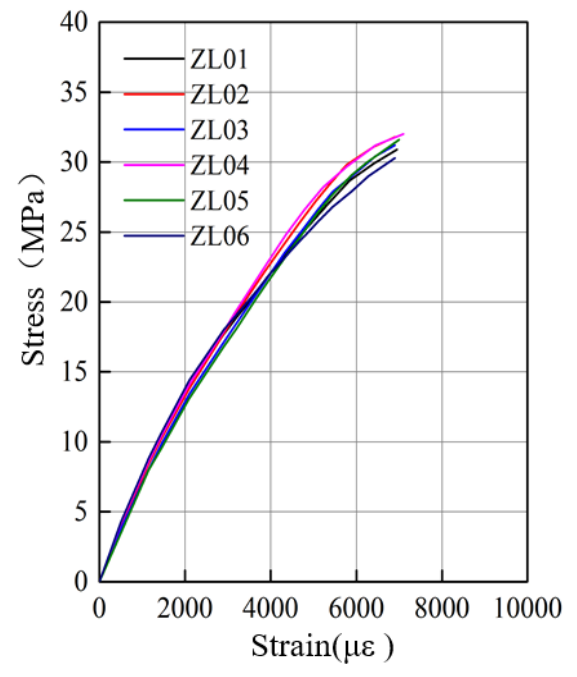

Fig. 12 - Direct tensile stress-strain curve

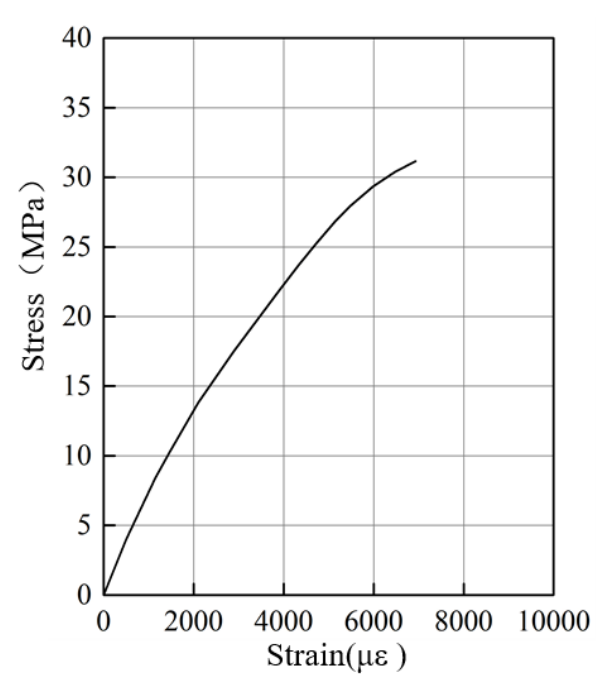

Fig. 13 - Stress-strain curve (average)

According to the stress and strain relationship points of axial tensile specimens, the stressstrain relationship curve is fitted, as shown in Figure 14. The fitting formula is as follows:

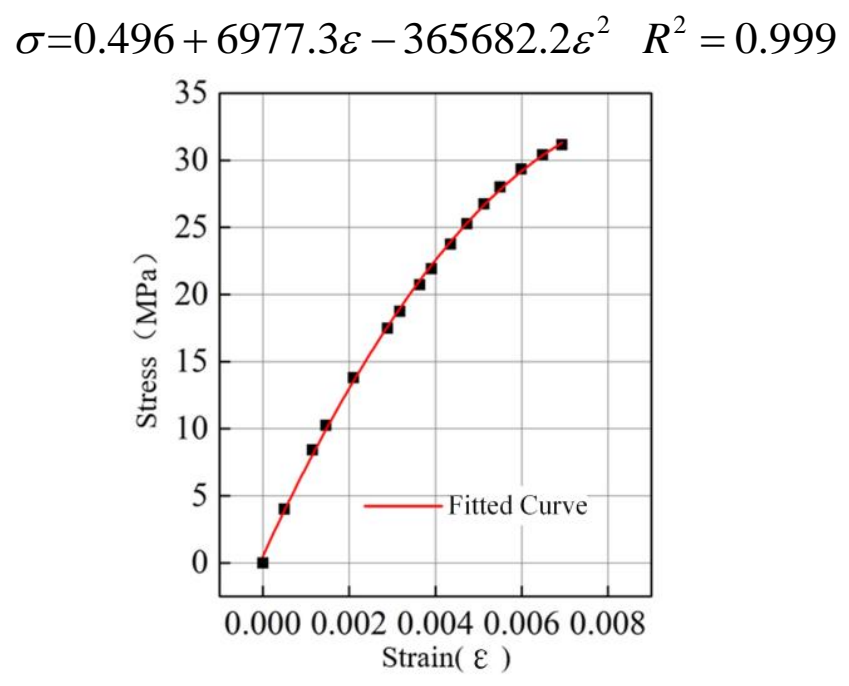

Fig. 14 - Fitting curve of axial tensile stress-strain relationship 


\section{Bonding test between material and concrete}

\section{Direct tensile bonding test}

First of all, the concrete is cut into $100 \mathrm{~mm} \times 100 \mathrm{~mm} \times 100 \mathrm{~mm}$ cube blocks with the concrete cutting machine to expose the aggregate of concrete and remove the floating ash on the surface of concrete. Then a $50 \mathrm{~mm} \times 50 \mathrm{~mm} \times 50 \mathrm{~mm}$ template with an inner cavity is made and placed on the concrete block so that the template is perpendicular to the concrete surface to avoid excess stress. Then place the $80 \mathrm{~mm}$ length bolt into the formwork so that the bolt center corresponds to the center of the concrete test block, as shown in Figure 16b. Finally, polyurethane cement material was poured into the formwork, and the wood formwork was removed after $7 \mathrm{~d}$. The number of the same test blocks is three. The size diagram of the test blocks is shown in Figure 15. The concrete block of the specimen is inserted into the custom fixture, the fixture tie rod is upward, and the specimen screw is downward. The fixture with the specimen is placed on the tension test machine, the fixture tie rod is placed in the upper jaw, and the specimen screw is placed in the lower jaw, as shown in Figure16a. In the process of tensile test, the ultimate tensile force of the specimen was tested.

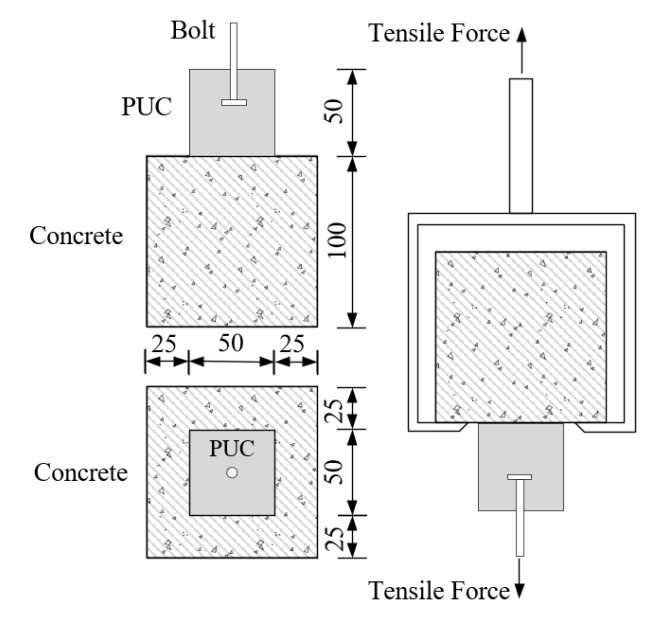

Fig. 15 - Schematic diagram of tensile bonding specimen size (unit: $\mathrm{mm}$ )

Calculate the axial tensile bond strength of polyurethane cement and concrete according to formula (2-3) :

$$
\sigma=\frac{F}{a b}
$$

$F$-Ultimate Tensile Force of the Specimen;

$a$ _ length of the contact surface between PUC and concrete;

$b$ _Width of the contact surface between PUC and concrete.

Tab. 6 - PUC material bonding strength table

\begin{tabular}{|c|c|c|c|c|}
\hline Number & ZN01 & ZN02 & ZN03 & Average value \\
\hline Strength (MPa) & 3.35 & 3.58 & 3.75 & 3.56 \\
\hline
\end{tabular}

The direct tensile bonding test results of PUC materials are shown in Table 6 . The bonding force between PUC material and concrete is larger than that of concrete material itself, and the average bonding stress is $3.56 \mathrm{MPa}$. In the tensile process, the concrete material itself will suffer bond failure, as shown in Figure 16c and Figure 16d. The failure interface does not occur on the bonding surface between concrete and PUC material, indicating that PUC material has good bonding property. 


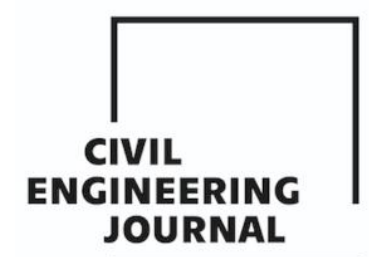

Article no. 42

THE CIVIL ENGINEERING JOURNAL 2-2021

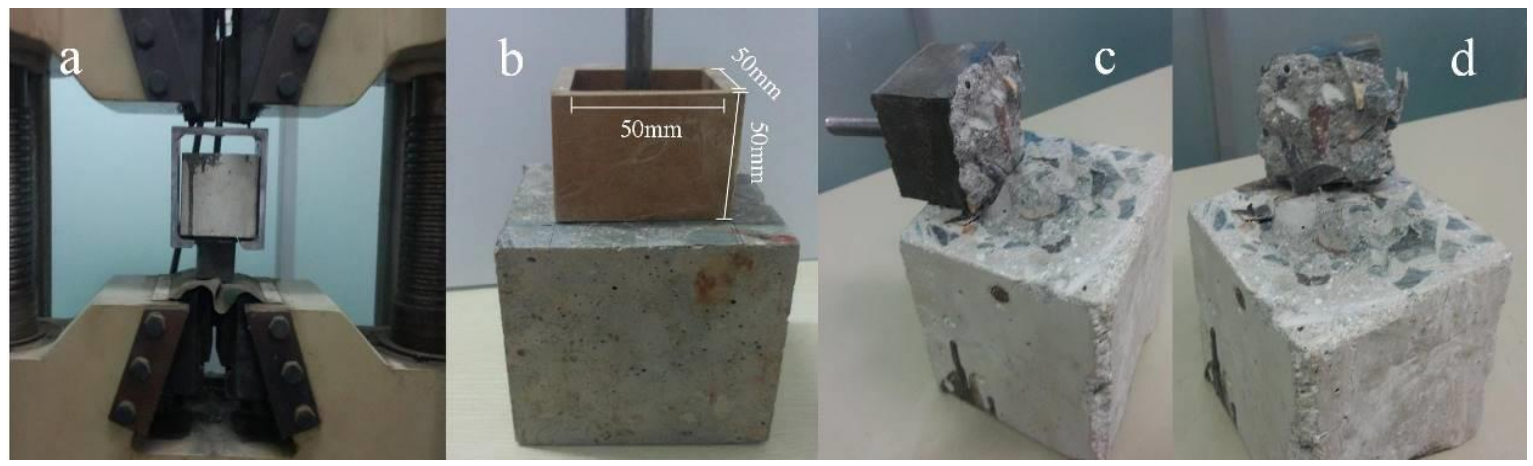

Fig. 16 - Test diagram of direct drawing bonding (Unit: $\mathrm{mm}$ )

\section{Bending bond test}

According to the method of bonding between polymer concrete and concrete tested by the Romanian National Institute of Building Research and Development [25], the bond test of PUC material was conducted. The casting of the bonding test blocks was completed in the $70 \mathrm{~mm} \times 70 \mathrm{~mm} \times 70 \mathrm{~mm}$ concrete triplet die. The cut $70 \mathrm{~mm} \times 70 \mathrm{~mm} \times 70 \mathrm{~mm}$ concrete test blocks were placed in both ends of the triplet die, and the PUC material was poured in the spare position in the middle, and the casting height was $60 \mathrm{~mm}$. The number of the same specimen is three, and the size of the specimen is shown in Figure 17 and Figure 18b. The universal testing machine was used for three-point loading, and the distance between the two fulcrum points was $160 \mathrm{~mm}$, so as to obtain the flexural strength of the specimen in the loading process, as shown in Figure 18a.

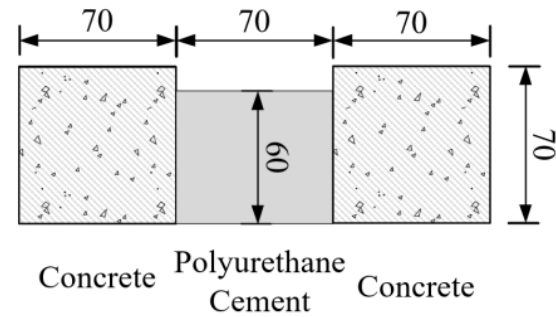

Fig. 17 - Schematic diagram of bonding test block size (unit: $\mathrm{mm}$ )

Calculate the axial tensile bond strength of polyurethane cement and concrete according to formula (4) :

$$
\sigma=\frac{3 F(l-a)}{b h^{2}}
$$

$$
\begin{array}{lll}
F & - & \text { Bending destructive force of the specimen; } \\
l & - & \text { Distance between two fulcrum points during loading; } \\
a & - & \text { Longitudinal length of PUC in the specimen; } \\
b & - & \text { Transverse width of PUC in the specimen; } \\
h & - & \text { Height of PUC in the specimen. }
\end{array}
$$

Tab. 7 - PUC material bonding strength table

\begin{tabular}{|c|c|c|c|c|}
\hline Number & WN01 & WN02 & WN03 & $\begin{array}{c}\text { Average } \\
\text { value }\end{array}$ \\
\hline Strength (MPa) & 3.15 & 3.08 & 3.25 & 3.16 \\
\hline
\end{tabular}

The bonding test results of polyurethane cement materials are shown in Table 7 . The bonding force between polyurethane cement material and concrete is higher than the bonding force of concrete material itself, and the average bonding stress is $3.16 \mathrm{MPa}$. In the process of bending, the 


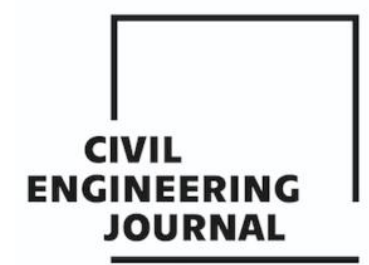

Article no. 42

THE CIVIL ENGINEERING JOURNAL 2-2021

bond failure of concrete material itself occurs, as shown in Figure 18c. The failure interface does not occur on the bonding surface between concrete and PUC material, indicating that PUC material has good bonding property.

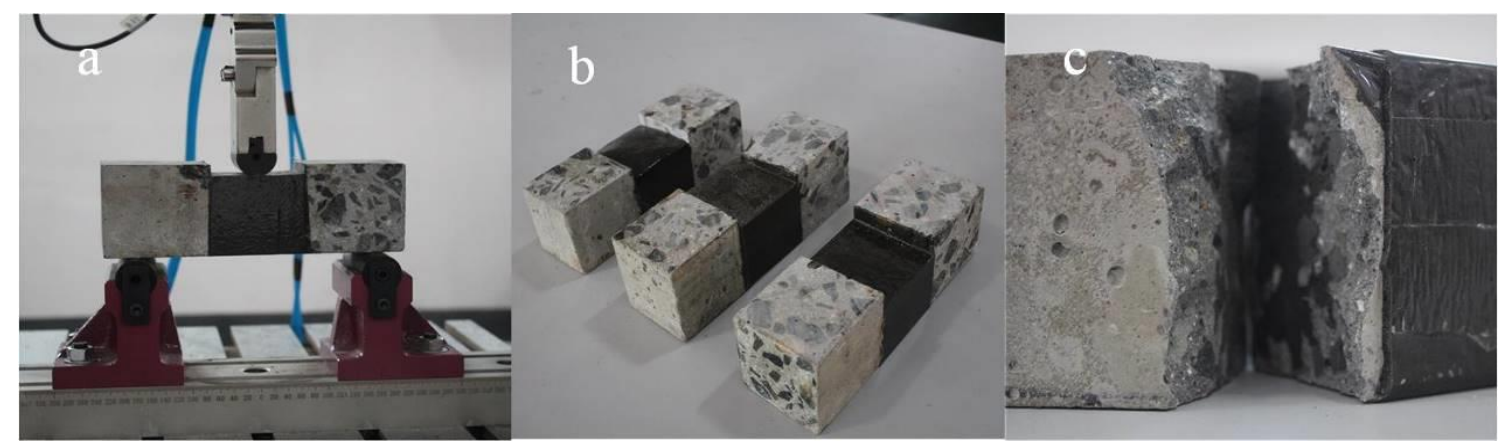

Fig. 18 - Bending bond test diagram

\section{Acid and alkali resistance test}

Two $40 \mathrm{~mm} \times 40 \mathrm{~mm} \times 160 \mathrm{~mm}$ test blocks were taken, both in the middle of the test blocks, for the chemical corrosion resistance determination of PUC-1550. Low-concentration and highconcentration acid-base solutions are configured, as follows:

$3 \%$ hydrochloric acid solution (volume fraction), $30 \mathrm{~g} / \mathrm{L}$ potassium hydroxide solution, $18 \%$ hydrochloric acid solution (volume fraction) and $100 \mathrm{~g} / \mathrm{L}$ potassium hydroxide solution.

The samples were put into an oven at $110^{\circ} \mathrm{C} \pm 5^{\circ} \mathrm{C}$ to dry. The difference value of weighing the test block for two consecutive times is no more than $0.1 \mathrm{~g}$, and then the test piece is cooled to the room temperature. The samples were then immersed in the test solution at a depth of $25 \mathrm{~mm}$ in each solution. The lid of the vessel is covered, and the soaked test samples are placed in the ambient temperature of $20^{\circ} \mathrm{C} \pm 2^{\circ} \mathrm{C}$, as shown in Figure 19. After immersed in the solution for $12 \mathrm{~d}$, the samples were taken out and washed with running water for $5 \mathrm{~d}$. Then, the samples were completely immersed in boiling water and boiled for $30 \mathrm{~min}$. After that, they were taken out and gently wiped with wringout but still wet suede, and then dried in a drying oven at $110^{\circ} \mathrm{C} \pm 5^{\circ} \mathrm{C}$.

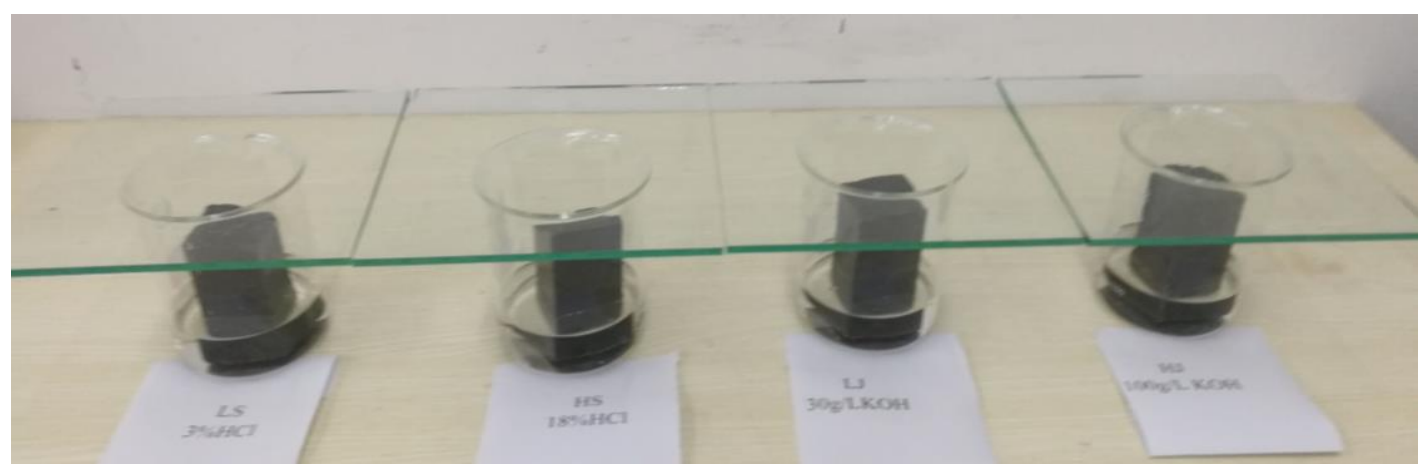

Fig. 19 - Chemical corrosion resistance determination

Tab. 8 - Chemical corrosion resistance determination

\begin{tabular}{|c|c|c|c|c|c|c|c|}
\hline Number & Solution & $\begin{array}{c}\text { Initial } \\
\text { mass }\end{array}$ & $\begin{array}{c}\text { Pre-test } \\
\text { quality }\end{array}$ & $\begin{array}{c}\text { Post- } \\
\text { test } \\
\text { quality }\end{array}$ & $\begin{array}{c}\text { Quality } \\
\text { loss }\end{array}$ & $\begin{array}{c}\text { Mass loss } \\
\text { rate }(\%)\end{array}$ & $\begin{array}{c}\text { Corrosion } \\
\text { resistance } \\
\text { grade }\end{array}$ \\
\hline $\mathrm{LS}$ & $3 \% \mathrm{HCl}$ & 94.76 & 94.59 & 94.47 & 0.12 & 0.127 & ULA \\
\hline $\mathrm{HS}$ & $18 \% \mathrm{HCl}$ & 82.85 & 82.71 & 82.54 & 0.17 & 0.206 & UHA \\
\hline $\mathrm{LJ}$ & $30 \mathrm{~g} / \mathrm{LOH}$ & 95.32 & 95.21 & 94.95 & 0.26 & 0.274 & ULA \\
\hline $\mathrm{HJ}$ & $100 \mathrm{~g} / \mathrm{L} \mathrm{KOH}$ & 77.18 & 77.05 & 76.73 & 0.32 & 0.417 & UHA \\
\hline
\end{tabular}

The test results of chemical corrosion resistance are shown in Table 8 . There is no visible change on the surface after immersion in solution of different concentrations. 


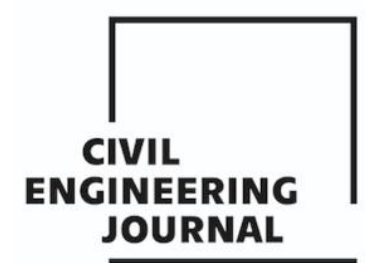

Article no. 42

THE CIVIL ENGINEERING JOURNAL 2-2021

\section{CONCLUSION}

In this paper, through the compression, bending, axial tensile, tensile bonding, bending bonding and chemical corrosion resistance tests of PUC material (PUC-1550) with a density of 1550 $\mathrm{kg} / \mathrm{m}^{3}$, the research results can provide material theory basis for bridge reinforcement and new structure bridge, the conclusions are as follows:

The mean compressive strength of PUC-1550 is $59.3 \mathrm{MPa}$, the mean flexural strength is 41.5 $\mathrm{MPa}$, the mean axial tensile strength is $31 \mathrm{MPa}$, and the Poisson's ratio of the material is 0.27 . The bending tension stress-strain curve and the axial tension stress-strain curve were obtained by fitting.

The average bond strength between PUC-1550 material and concrete is $3.56 \mathrm{MPa}$ through the axial tensile bond test, and 3.16 MPa through the bending bond test. The failure interface of the two bonding tests did not occur on the bonding surface between concrete and PUC material, indicating that polyurethane cement material has good bonding property.

Chemical corrosion resistance test was carried out in different concentrations of acid and alkali solution. The results show that the PUC surface has no visible change and it has good chemical corrosion resistance.

\section{ACKNOWLEDGEMENTS}

Thank You for the Open Fund project of key Laboratory of Ministry of Education for Disaster and Control of Major Engineering, Jinan University (20200904012)

\section{REFERENCES}

[1] Wang, E. L. ,2018. Construction monitoring on steel truss bridge's maintenance and reinforcement. Applied Mechanics and Materials, 878, 89-94.

[2] Liu, J.,2015. The detection evaluation and reinforcement research of kankan river bridge. Engineering, 07(7), 462-468.

[3] Yeh, C. K. , \& Lin, H. T., 2016. Automatic bridge bidding using deep reinforcement learning. Journal of Lightwave Technology.

[4] Fang R, Yang X.,2015. Cause and Countermeasure of Structure Disease of Bridge[C]// International Conference on Transportation Information \& Safety.

[5] Diao, Yan.,2014. Stone Arch Bridge Disease Detection and Evaluation[J]. Applied Mechanics \& Materials, 501-504:1332-1335.

[6] Zhongqiu F, Guyu S, Tong S, et al.,2017. Research on Fatigue Diseases Evation of Steel Bridge Deck Based on Fuzzy Comprehensive Method [J]. Industrial Construction.

[7] Hui M C H , Wong C K P.,2009. Stonecutters Bridge-Durability, Maintenance and Safety Considerations[J]. Structure \& Infrastructure Engineering, 5(3):229-243.

[8] Cheng, Kang.,2002. Modeling and Simulation of Bridge Stability Based on Deep Learning[C]// 2018.

[9] Gui, C. , Zhang, J. , Lei, J. , Hou, Y. , \& Qian, Z. . (2021). A comprehensive evaluation algorithm for project-level bridge maintenance decision-making. Journal of Cleaner Production, 289, 125713.

[10] Lee W F , Chen C H , Chang C F , et al.,2010. Bridge Monitoring and Safety Evaluation Method Using a Vibration Thchnique [J].

[11] Utsunomiya T., 2004. Bridge Maintenance, Safety, Management and Cost[J].

[12] Wang Y, Zhu X, Hao H, et al.,2009. Corrosion-induced Cracking of Reinforced Concrete Beam : Experimental Study[J]. Applied Mechanics \& Materials, 256-259(12):1148-1153.

[13] Sonoda K , Okino M , Hayashi H , et al.,2010. Reliability of Epoxy Bonded Steel Plate Method for Repairing Damaged RC Slabs of Bridge[J]. Proceedings of the Japan Society of Civil Engineers (398):245254.

[14] Zhao S W , Qiao X P.,2011. Experimental Study on Reinforced Hollow Beam with Carbon Fiber Reinforced Polymer and External Prestressed Strand[J]. Applied Mechanics \& Materials, 94-96:495-499. 


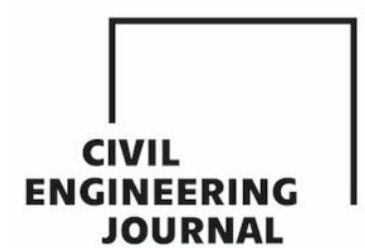

Article no. 42 JOURNAL

\section{THE CIVIL ENGINEERING JOURNAL 2-2021}

[15] Zhishen G, Wei, et al.,2014. Flexural strengthening of RC beams using distributed prestressed high strength steel wire rope: theoretical analysis[J]. Structure \& Infrastructure Engineering: Maintenance, Management, Life-Cycl.

[16] Yongqing Y, Meng Y, Xiaobin L.,2014. Theoretical and Experimental Study of Load Transverse Distribution of Hollow Slab Bridge Strengthened by Modified Polymer Concrete[J]. Bridge Construction , 44(6): 63-68.

[17] Jianlin W, Guiwei L, Lishui Y.,2013. Research on the application technology of strengthening hollow slab bridge with MPC composite material[J]. Highway, 8: 39-43.

[18] Hongxiang Z, Chao C , Tianlai Y.,2015. The application of simply supported $T$ beam strengthended by MPC [J]. Low Temperature Architecture Technology, 3: 59-61.

[19] Feng G. An experimental study on strengthening reinforced concrete hollow-slab girder using new material polymethane-cement (PUC) [D]. Harbin Institute of Technology, 2016.

[20] Dandan G, Quansheng S.,2015. Study of Static Tests for Using MPC Composite Material to Strengthen Void Plate Girder Bridge[J]. World Bridges, 43(6): 88-92.

[21] Jiancai G, Yanqun Z, Bingjun C, Guiwei L., 2017. Reinforced concrete solid slab girder bridge reinforced with MPC composite materials[J]. Highway, 3: 126-130.

[22] Haleem K. H, Lianzhen Z, Guiwei., 2013. An experimental study on strengthening reinforced concrete T-beams using new material poly-urethane-cement (PUC) [J]. Construction and Building Materails, 40: 104-117.

[23] Haleem K. H, Guiwei L, Yuwen Y., 2014. Experimental study to investigate mechanical properties of new material polyurethane-cement composite (PUC)[J]. Construction and Building materials, 50: 200-208.

[24] Liu G, Otsuka H, Mizuta Y, Shimitsu A., 2006. A Foundational Study on Static Mechanical Characteristics of the Super Lightweight and High Strength Material Using Fly-ash[J]. Journal of the Society of Material Science Japan, 55(8):738-745.

[25] Leon Agavriloaie, Stefan Oprea, Marinela Barbuta, Florentina Luca. Characterisation of polymer concrete with epoxy polyurethane acryl matrix[J]. Construction and building materials, 2012, 37: 190-196. 